\title{
Exploring Partnerships in Early Childhood Teacher Education through Scenario-based Learning
}

\author{
Reesa Sorin ${ }^{1, *}$ \\ ${ }^{1}$ School of Education, James Cook University, Cairns, Australia \\ *Correspondence: School of Education, James Cook University, PO Box 6811, Cairns, Queensland 4870, Australia \\ E-mail: reesa.sorin@jcu.edu.au
}

Received: December 27, 2012

Accepted: January 16, $2013 \quad$ Online Published: January 29, 2013

doi:10.5430/wje.v3n1p39

URL: http://dx.doi.org/10.5430/wje.v3n1p39

\begin{abstract}
Belonging to "a family, a cultural group, a neighbourhood and a wider community" (Department of Education, Employment and Workplace Relations [DEEWR], 2009, p. 7) is integral to children's early development and learning. Acknowledging families as "children's first and most influential educators" (DEEWR, 2009, p. 7), DEEWR notes that, "as children participate in everyday life, they develop interests and construct their own identities and understandings of the world" (Ibid). So, when children transition from the family context to participate in early education, establishing and maintaining partnerships with families and community members is essential to early childhood pedagogy. The Early Years Learning Framework acknowledges, "Belonging is central to being and becoming in that it shapes who children are and who they can become" (Ibid).

While an important component of education, professional topics such as partnerships can be given less priority in university subjects that focus on curriculum components. To "bridge perceived gaps between subject theory and professional practice" (Errington, 2010, p. 17) professional topics can be explored through scenario-based learning. This paper presents findings about the understanding and implementation of partnerships through scenario-based learning in a third year, online early childhood education subject, "Early Childhood Education and Care 2". The research question was, "How can scenario-based learning be implemented to increase students' understanding and practice of partnerships?"
\end{abstract}

Keywords: scenario-based learning; early childhood teacher education; partnerships in early childhood

\section{Introduction}

\subsection{Partnerships in Early Childhood Education}

According to sociocultural theory, children's learning is situated within the social and cultural contexts of families and communities (Arthur, Beecher, Dockett, Death \& Farmer, 2012). Through watching and interacting with families and communities, children learn the social and cultural practices of their society and how to engage with them. Awareness of these contexts by early childhood teachers helps to bridge the gap between home and school and to inform classroom practice that extends children's learning. "When educators are aware of children's interests, experiential learning and knowledge networks within their families and communities, there is more likely to be congruence between children's family and educational contexts" (Arthur et al, 2012, p. 48). This awareness is created through establishing effective partnerships with families and community members, so that children's real world knowledge and experiences can be linked to and included in classroom practice and they are able to demonstrate their understandings and actively participate in classroom learning (Arthur et al, 2012).

Partnerships with families and community members are more than just teachers acknowledging the roles of families and communities in children's learning and development; they are built upon partners understanding and valuing each others' knowledge, attitudes and expectations. DEEWR (2009) describes genuine partnerships as ones where partners:

- value each other's knowledge of each child

- value each other's contributions to and roles in each child's life 
- trust each other

- communicate freely and respectfully with each other

- $\quad$ share insights and perspectives about each child, and

- $\quad$ engage in shared decision-making (p. 12).

Professional Standards (Queensland College of Teachers [QCT], 2006) guide teaching practice in the state of Queensland in Australia. Standard 8 is "Foster positive and productive relationships with families and communities". Practice includes "establish respectful, productive and cooperative relationships with families, caregivers and other community members to support student learning and well-being" and knowledge includes: "strategies for developing and maintaining partnerships and effectively communicating with families, caregivers and other community members" and "strategies for involving families, caregivers and other community members in the design, implementation and review of learning programs" (p. 14).

Partnerships go beyond parent involvement, where families are expected to conform to the expectations of the teacher and classroom, to opportunities for families: to contribute to developing the philosophy, goals, policies and program; to share in documenting children's learning; to connect school curricula to home and community experiences; to exchange information with teachers about children's interests, attitudes and relationships; and to link families with community organizations and networks (Arthur et al, 2012).

The Australian Children's Education and Care Quality Authority (ACECQA) note that "learning outcomes are most likely to be achieved when educators work in partnership with families and communities" (2011, p. 147). Educators are encouraged to get to know the diversity of families, to nurture the child/ family relationship and to collaborate effectively through two-way communication about children's interests, strengths and abilities as well as ways to extend their learning (Ibid). "Partnerships also involve educators, families and support professionals working together to explore the learning potential in every day events, routines and play so that children with additional needs are provided with daily opportunities to learn from active participation and engagement in these experiences in the home" (DEEWR, 2009, p. 12).

\subsection{Partnerships and Scenario-based Learning (SBL)}

Understanding of professional topics such as partnerships is essential to Early Childhood Education students' growing professional identities. Errington (2008) notes, "It is crucial that aspiring professionals are able to envision and explore alternative futures - to develop the kind of flexibility needed to tackle events and issues from a professional perspective" (p.5). Education students complete between 80 and 100 days of professional experience during their four years of university study. During this time, there are some opportunities to get to know the families and communities of the children in their classes. Yet many students still report a lack of understanding of partnerships. "I thought that it was just working together [with parents] and sharing information", reported a third year student. O'Brien and Goddard (2005 in Adam, 2010) report "that many beginning teachers feel unsupported and unprepared for the transition from university to school" (p.97).

Because of this, 'partnerships' was one of the professional topics selected for study in the third year, university-based subject, Early Childhood Education and Care 2. Even with an increase in theoretical content to address priorities such as literacy, numeracy, environmental sustainability and indigenous education, university subjects need not be removed from 'real world' classroom practice. Adam (in Errington, 2010) suggests, "University-based theory and classroom practice are by no means mutually exclusive categories. There is a certain 'complementarity' that is perhaps most productive at the nexus between the two" (p. 97).

Scenario-based learning (SBL) is ideally located at this nexus, as a way to enhance the professional development of Early Childhood Education students. As Errington (2008) suggests, scenarios are good ways to explore and develop professional identity. "Scenarios allow for a questioning of 'identity' (roles, responsibilities, assumptions), when students are afforded the opportunity to challenge conventional wisdom" (p. 5).

Scenarios are authentic "glimpses" of everyday issues. They are often written or told as narratives, and provide situated learning in "real world" contexts that is, according to Lave and Wegner (1991), an important component for knowledge acquisition. Scenario-based learning approaches are applicable not only to future teachers, but to many other professions, particularly those with challenging work situations where there is not one solution, but diverse ways to address problems. Scenarios permit learners to safely explore situations they might face in their future classrooms (Alessi \& Trollip in Hunter, 2009), to apply theory to practice and to trial ways of responding to these situations.

A scenario-based approach is dynamic and non-linear (Akins \& Crichton, 2003). Scenarios arouse curiosity and 
stimulate learning through their stories (Hunter, 2009), making them ideal for online learning environments. Scenario-based learning is a natural byproduct of "authentic activities that are common to the community of practice in which the learner is involved" (Hebron in Kindley, 2002, 3).

Authenticity comes from making scenario contexts as realistic as possible (Akins \& Crichton, 2003); to provide a vehicle for learners to engage with 'real world' problems (Damoenese, 2003) through collaborative learning teams, or "communities of practice." According to Lave \& Wenger (1991), learning is an ongoing professional socialization process within a community of learners.

Scenario-based learning is inductive - the scope of learning is not predetermined. Through their investigations, learners determine successful or unsuccessful outcomes. It is here that previous knowledge and experience become valuable and valued (Akins \& Crichton, 2003). Beyond the given information and learners' prior experiences, further information can be accessed from a variety of sources. There is not one set answer or pathway to solutions.

A scenario-based approach suits complex topics with problematic solutions (Akins \& Crichton, 2003). It offers instructors a creative challenge - to develop the story, gather supporting materials and give direction for further investigation. While preparation involves considerable work, rewards to learners include: deeper learning through sharing knowledge in a community of learners; strong links made between theory and practice; and a chance to safely "practice" the roles for which they are preparing (Errington, 2010). Scenarios make learning fun and engaging.

\section{Method}

Scenarios were introduced into Early Childhood Education and Care 2, an online third year subject, to help students to explore professional topics within their classroom learning community. Errington (2008) notes the important role scenarios can play in identity formation, as they facilitate "a growing ability for students to interact with all kinds of situations and people within the quasi-professional setting" (p. 5). By experiencing professional topics through scenarios, it was anticipated that students would match their prior experience and beliefs about teaching and learning with their growing sense of professional identity as early childhood teachers.

Scenario topics were based on moral and ethical issues teachers may encounter in their day-to-day professional lives, such as partnerships, ethics, child protection, bullying and brain development. According to Lave and Wenger (1991), novices must have access to arenas of mature practice and must become a part of the community to truly engage with the learning. In scenarios developed for this subject, knowledge was not given; it was something to be discovered through solving the problem(s) and making sense of the situation. Information and support material accompanied each scenario, but were purposely incomplete, as would be the case in 'real life', where teachers are privy to some, but not all information.

Learning required immersion in the situation, action, feedback and further action (Kindley, 2002). In each scenario, students worked in small groups of 5 and were asked to take on the role of the early childhood teacher and/or other characters in the scenario; to engage, think deeply, collaborate, make decisions and create options for solving the problems.

Assessment of understanding took the form of individual and group tasks, such as staff presentations, letters to parents, and reports to the principal. In the partnership scenario, the assessment tasks required students in small groups to write an acceptance speech for an inclusive practice award, and individually to describe how partnerships could be implemented to early years learning outcomes.

\subsection{The Partnership Scenario}

The Partnership Scenario was developed with input from early childhood teachers and consultants, and a community participation officer whose job it was to liaise with parents and teachers. It read:

It is your second year of teaching and you are in a Year 3 class in a rural school. In the time you've been there, you've gotten to know some of the families, who are mainly farming families. They are very friendly, but they tend to leave the teachers to do the teaching, preferring to raise money for the school by helping out at the school fete. Then there is Helene, the exception to the rule.

Daniel's mum, Helene, must have a lot of time on her hands. She is forever reading parenting magazines and searching through education websites, then sending you photocopied articles to read in Daniel's lunchbox. She keeps asking if she can help in the class and she even thinks that Daniel is "gifted". He never seems to listen to you, and you think he's just a bit spoilt and restless. 
You wish Helene would just stick to helping her kids with their homework and listening to them read, but she seems to always be questioning you about what you are teaching and why, and offering her opinions of other methods, etc. You find you are starting to question yourself as well, and you try to avoid this mother when she drops her children off or picks them up. You feel that she shouldn't butt in and should know her place as a parent. Besides, if she stays at home and has all that time, and she thinks she's so knowledgeable about education, why doesn't she go to uni and do a teaching qualification?

Group Response (no marks allocated):

It is the year 2016. Your Kindergarten has been showcased by Early Childhood Australia for the effective partnerships with parents that you and the other kindergarten teacher, Helene, have established with parents and the community. You and Helene will be presented with an award at the Early Childhood Australia national conference in Cairns. As a group, write your acceptance speech, describing the process of establishing partnerships and how they currently work in your kindergarten.

Individual Response (marks allocated for assessment purposes):

Describe partnerships with families and community members that would help to develop young children as: a strong child; a skillful communicator; a competent learner; and a healthy child.

\subsection{Data Collection}

All scenarios were accompanied by a range of support materials. These included information similar to lecture notes; multimedia resources such as video clips and podcasts; children's work samples; personal anecdotes; library reserve readings; and links to academic journal articles, useful websites and online resources. These materials provided a foundation to understanding the scenarios, but required further research to deeply understand the topic. Each group was given an online discussion site where information and ideas could be shared.

Following subject delivery, students were surveyed about the scenarios, with particular emphasis on the partnerships scenario. The research question was, "How can scenario-based learning be implemented to increase students' understanding and practice of partnerships?" Students were asked about their prior knowledge and experience with partnerships; what they had learned from the partnerships scenario, and how their learning had impacted on their practice. The online survey was set up so that students could respond anonymously if they did not wish for their identities to be known. Findings are presented below.

\section{Results}

This section reports on students' responses to the following questions:

Prior to undertaking the partnership scenario, what was your prior knowledge of partnerships?

What have you learned from the partnerships scenario?

How (if at all) has your learning about partnerships through the scenario impacted on your teaching practice?

What did you think of the process of scenario-based learning for learning about partnerships?

\subsection{Prior Knowledge of Partnerships}

Amongst the students - some of whom had entered university directly from high school, while others had worked, raised families and returned to study after a number of years - prior knowledge and experience with partnerships varied. Some reported experience with partnerships from previous and current work:

I have worked for 10 years with four different teachers one on one as an assistant working in one class...I knew that the relationships that are formed as part of these partnerships are what create a positive work place and a positive learning environment for children and adults.

Others reported experience with partnerships as both an educator and parent:

I have 11 years experience working in schools, and as a mother I have first hand knowledge of partnerships with the system...I have had the opportunity to work along other parents in my role as a member of $P \& C$ [Parent and Citizens] committee for 4 years and also in my capacity as a Teacher Aide. I have established strong partnerships with parents and with other staff members to ensure that through the sharing of dialogue we can provide better opportunities for the children in my care.

I had experienced what it means to be a 'partner' with my own children and their teachers in formal education settings; 
and as a preservice teacher during professional experience.

Still others reported limited experience and/or understanding with partnerships:

I knew that teachers have to build partnerships with students, families, other teachers and the community.

[My previous] understanding of partnerships with families simply involved getting them to assist in classroom activities... I never experienced partnerships with other teachers.

I didn't know that much, I thought that it was just working together and sharing information.

\subsection{Learning from Scenarios}

When asked what they had learned from the partnerships scenario, student responses included deeper understanding about professional partnerships, and accepting and valuing of others' ideas and opinions. This was largely through the process of working together in small groups to explore the scenario:

\subsubsection{Deeper Knowledge and Understanding}

Deeper understanding of partnerships included the importance and complexity of establishing partnerships:

The complexities involved in fostering partnerships; that it is not as simple as inviting parents to help out in the classroom, relationship is build on 'mutual benefit'.

The importance of positive relationship building with all partners involved. The importance of reflecting on teaching practices. Awareness of the different types of partnerships and teamwork. I hadn't thought about global community as a part of a partnership previously. How important it is from the first day to build positive relationships with parents and treat them as authentic partners in the education of their child.

I realised that there is a lot more that is involved in partnerships, including shared resources, scaffolding each other, various purposes and people that they can be formed with, time benefits and that we can find and achieve more accurate results to make more informed decisions.

The scope and processes of partnerships were also reported:

I learned partnerships extended to incorporating families, teachers and children into important decision making of classrooms and schools. As such, a collective classroom culture is established that reflects a diversity of ideas/perspectives. This is an ideal environment since it challenges the assumption that hegemonic values should dominate classroom practice, as such curriculum not only connects to children with cultural capital, but also to children of minority groups.

I understand the legalities involved and also how better to involve parents as partners in education. This knowledge has and will give me increased confidence in dealing with partners. I have a better understanding of my role also.

\subsubsection{Broadened Views and Practice}

Beyond knowledge and understanding of partnerships - their importance, complexity, scope and processes, students reported that participating in the scenarios broadened their views and made them more accepting of others' views:

It assisted in broadening my views and to engage in conversations with other students to build knowledge, share opinions and question responses to formulate new opinions...I think it was an eye opener in terms of being open to other people's interpretations and having the tolerance to accept other views...It has allowed me to be more open, accepting and value the difference between individuals.

While these students were still over a year from entering the teaching field at the time of the survey, some felt that the scenario had impacted on their practice:

When I go into a new school environment I am aware of the partnerships that are already existing and I try to build positive partnerships with the staff, the class teacher, the students and their parents...I think because we focused on partnerships at uni, it sits in my mind when I'm on prac, whereas if we hadn't, I may have just blundered along and not really have developed good knowledge of what makes partnerships work and never really have thought about it until a problem happened.

My group work and communication skills have improved.

Researching and discussing answers to realistic situations led me to find relevant information and resources that I can use in the future. Through this process I also am more aware of where to find information for future situations I know I may face.

Student reports indicated that through participating in the partnership scenario they had acquired more content 
knowledge and better communication and group work skills. Many also reported attitudinal changes, such as becoming more accepting and valuing of others, their ideas and opinions.

\subsubsection{Authenticity}

Overall, students found the partnership scenario and accompanying tasks "very relevant to real life situations, therefore they were very useful to engage with." They reported that scenarios helped them to make an authentic connection to their professional lives. One student commented, "[Scenarios] are most beneficial and connect our learning to the real world."

\subsubsection{Concerns}

However, some students expressed concern over aspects of the scenarios: the amount of information presented in the scenario; group work; and no marks being allocated to the group response. Regarding the amount of information presented, comments included:

Scenarios needed more information as most of them required a lot of assumptions, such as children's age, how long they have been at the school, how much involvement we have with the next door neighbour [in another scenario], etc.

I do not believe they gave us enough info[rmation].

Working in a group was an issue for some, who felt that their input was compensating for others, who did very little. Comments included:

Being forced to work as a group...was a complete waste of time.

It is very easy to 'hide' in cyberspace. This places pressure on the rest of the group.

Comments about no marks being allocated to group work included:

There was a lot of work put into [group] presentations and it would have been nice for them to be worth some marks towards our overall mark.

The amount of information presented in the scenarios was critically reflected on and, after further explored through peer scenario review. One peer noted that the scenario was "packed with information" and cautioned not to overwhelm learners with too much material. Another suggested that information be presented in segments, each with a focus question. A third suggested that more anecdotes of similar events be presented to give a broader view of how professionals have handled similar situations. Since this review and reflection, support materials have been refined and updated, but are still incomplete to allow students the opportunity to self-direct their learning. Group work was not always seen as favourable, due to varying participation by group members and no marks being given for group work, contributing effectively to professional teams is a professional standard for teachers in Queensland (QCT, 2006). Therefore it remained a part of the SBL process, but was allocated marks. Each year, scenarios are re-examined and updated, based on student and peer feedback and critical reflection, and to include current research, policy and practice. SBL continues to be implemented to address gaps between theory and professional practice (Errington, 2010).

\section{Discussion}

Developing genuine partnerships with families and community members is an important component of early childhood teaching. Partnerships present opportunities for educators to become aware of children's backgrounds, experiences and interests and to bring this understanding to what they include in classroom practice. While some experience of partnerships might occur during students' professional experiences in classrooms, it is critical that students develop a deep understanding of partnerships so that they are able to develop them in their future classrooms.

Scenario-based learning provides a good opportunity for early childhood education students to explore professional development topics and bridge the gap between theory and practice, as they become situated in 'real world' events that require them to take on the role of the teacher, to engage, think deeply, collaborate, make decisions and solve problems.

Scenario-based learning was implemented and researched, as a way of developing understandings about partnerships in early childhood education. The research question was, "How can scenario-based learning be implemented to increase students' understanding and practice of partnerships?"

While many students reported some understanding of partnerships prior to undertaking the scenario, most reported a deeper understanding of the topic because of the scenario. Further, the process of working in small groups on the 
partnership scenario broadened student views and helped them to become more accepting and valuing of the views of others. Many felt that participating in the scenario had impacted their teaching practice; they were more informed, willing and able to establish partnerships with parents and community members in their future practice. Concerns about SBL included the amount of information provided group work and marking allocation, and these concerns have been critically reflected on and practice within SBL modified.

SBL will continue to be developed, implemented and researched to enhance the learning of Early Childhood Education students, as they explore and develop their professional identities. Scenarios provide authentic, dynamic learning opportunities. As one student reported, "I feel privileged to have participated in [SBL] and a lot more knowledgeable and prepared if ever faced with similar situations."

\section{References}

Akins, M., \& Crichton, S. (2003). Scenario Based Learning - Geography in the Field Using GIS / GPS for Curriculum Integration. Washington, USA: National Educational Computing Conference.

Arthur, L., Beecher, B., Death, E. Dockett, S., \& Farmer, S. (2012). Programming and Planning in Early Childhood Settings. South Melbourne, Victoria: Cengage.

Australian Children's Education and Care Quality Authority (ACECQA). (2011). Guide to the National Quality Standard. Retrieved from http://acecqa.gov.au/national-quality-framework/

Australian Government Department of Education, Employment and Workplace Relations (DEEWR). (2009). Belonging, Being and Becoming - The Early Years Learning Framework for Australia. A.C.T., Australia: Commonwealth of Australia.

Errington, E. (2008). Mission Possible: Using near-world scenarios to prepare graduates for the profession. Journal of Teaching and Learning in Higher Education, 23(1), 84-91.

Errington, E. (ed). (2010). Preparing graduates for the professions using scenario-based learning. Brisbane: Post Pressed.

Hunter, B. (2009). The Benefits of Simulation-based eLearning. Workstar. Retrieved online 1/5/09 from www.impart.com.au/workstar/workstar/knowledgecentre/articlesandtakeaways.html

Kindley, R. (2002). Scenario-Based E-Learning: A Step beyond Traditional E-Learning. Retrieved 30/4/09 from http://www.learningcircuits.org/2002/may2002/kindley.html

Lave, J., \& Wenger, E. (1991). Situated learning - legitimate peripheral participation. Melbourne: Cambridge University Press. http://dx.doi.org/10.1017/CBO9780511815355

Queensland College of Teachers. (2006). Professional Standards for Queensland Teachers (graduate level). Retrieved from http://www.qct.edu.au/standards/index.html 